\title{
BMJ Open Quality Testing and implementing video consulting for outpatient appointments: using quality improvement system thinking and codesign principles
}

\author{
Clare Morrison, ${ }^{1}$ Michelle Beattie, ${ }^{2}$ Joseph Wherton, ${ }^{3}$ Cameron Stark, ${ }^{4,5}$ \\ Julie Anderson, ${ }^{6}$ Carolyn Hunter-Rowe, ${ }^{7}$ Nicola M Gray (i) ${ }^{8}$
}

To cite: Morrison C, Beattie M, Wherton $\mathrm{J}$, et al. Testing and implementing video consulting for outpatient appointments: using quality improvement system thinking and codesign principles. BMJ Open Quality 2021;10:e001259. doi:10.1136/ bmjoq-2020-001259

- Additional material is published online only. To view, please visit the journal online (http://dx.doi.org/10.1136/ bmjoq-2020-001259).

Received 29 0ctober 2020 Revised 16 February 2021 Accepted 22 February 2021
Check for updates

(C) Author(s) (or their employer(s)) 2021. Re-use permitted under CC BY-NC. No commercial re-use. See rights and permissions. Published by BMJ.

For numbered affiliations see end of article.

Correspondence to Dr Nicola M Gray; n.y.gray@dundee.ac.uk

\section{ABSTRACT}

Increasing demand for outpatient appointments (OPA) is a global challenge for healthcare providers. Non-attendance rates are high, not least because of the challenges of attending hospital OPAs due to transport difficulties, cost, poor health, caring and work responsibilities. Digital solutions may help ameliorate these challenges. This project aimed to implement codesigned outpatient video consultations across National Health Service (NHS) Highland using system-wide quality improvement approaches to implementation, involving patients, carers, clinical and non-clinical staff, national and local strategic leads. System mapping; an intensive codesign process involving extensive stakeholder engagement and realtime testing; Plan, Do, Study, Act cycles; and collection of clinician and patient feedback were used to optimise the service. Standardised processes were developed and implemented, which made video consulting easy to use for patients, embedded video into routine health service systems for clinicians and non-clinical staff, and automated much of the administrative burden. All clinicians and staff are using the system and both groups identified benefits in terms of travel time and costs saved. Transferable lessons for other services are identified, providing a practical blueprint for others to adapt and use in their own contexts to help implement and sustain video consultation services now and in the future.

\section{PROBLEM}

The aim of this project was to develop an embedded a video consultation service within the existing National Health Service (NHS) outpatient system, that was easy to use for both patients and NHS staff, and that could be adopted routinely.

NHS Highland (the context of this project) provides healthcare for a remote and rural population of 320000 people ( $6 \%$ of the Scottish population) over $42 \%$ of the land mass of Scotland, making it one of the largest and most sparsely populated health services in the UK. ${ }^{1}$ Although some remote outpatient clinics are provided, this often results in fewer patient consultations being available due to clinician travel time, thus most outpatient appointments (OPAs) in NHS Highland are delivered in a single urban centre (Inverness), which places the burden of travel mostly on patients. For patients who live in the more rural parts of the Highlands, this may mean travelling 3 hours each way to attend a brief (less than $10 \mathrm{~min}$ ) OPA. For patients who live on the islands, the journey may take 2 days. For example, in 2017 over 10000 patient journeys a year were being made from Caithness to Inverness for OPAs (over 200 miles round trip). ${ }^{2}$ This is an inconvenience for patients who feel well, but a significant challenge for people who are frail or in pain.

The development of the outpatient intervention arose as a result of public and patient opinion to reduce lengthy travel, the availability and advancement of technology, national policy for outpatient reform and an organisational drive for quality improvement. One of the authors (CM) used a new video consulting platform called Attend Anywhere (which had just been made available to NHS Scotland) to develop a pharmacy consulting service, ${ }^{3}$ which enabled patients living in rural locations to have a consultation with a pharmacist over 100 miles away using telehealth. The success of this project resulted in a wider project being commissioned to develop an outpatient's video consulting service across NHS Highland. The availability of the Attend Anywhere video consultation platform helped to address many of the technical concerns previously identified. What was lacking were the systems and processes to enable its' effective use, this was the focus for the Near Me quality improvement project reported in this paper.

\section{BACKGROUND}

The increasing demand for OPA is a global challenge for healthcare providers. ${ }^{45}$ In the last 10 years in the UK, there has been a $65 \%$ 
increase in demand, which is expected to continue, ${ }^{6-8}$ however, non-attendance rates for OPA can be high, varying from $10 \%$ to $40 \% .{ }^{9}$ In part, non-attendance may be due to the challenges for patients of getting to the OPA due to limited transport options, poor physical or mental health, caring and work responsibilities.

To help ameliorate the challenges to both patients attending and services delivering outpatient care, there has been a strong move, particularly at a $\mathrm{UK}^{10}$ and Scottish policy level, ${ }^{11}$ towards the use of digital solutions. One of the priorities for NHS Scotland is to improve outpatient services, including 'facilitating more return or follow-up appointments in non-hospital settings through virtual consultation from their own home'. ${ }^{12}$

Published research on video outpatient consultations shows great potential in terms of acceptability, safety and effectiveness in patients considered clinically eligible across a range of conditions. ${ }^{13-32}$ But much of this literature tends to be technology focused (ie, classifying service models primarily by the nature of the technology and secondarily by the task supported by that technology) or does not provide the level of in-depth understanding of the (often subtle) social and technical challenges to implementation and 'scaling up' of the service model. Organisational case studies have shown that introducing video consultations is a complex change that disrupts long established processes and routines. ${ }^{33-36}$ Implementation requires practitioners to adapt to the new ways of consulting with patients through video technology. ${ }^{37} 38$ Some clinicians also express concerns about technical and clinical quality, privacy, safety, and real and perceived information governance challenges. ${ }^{39}$

There are increasing expectations that the public will be involved in the commissioning, designing and improving health and social care systems, the NHS Scotland 'Digital Health and Care Strategy ${ }^{40}$ emphasises the need for 'local service change and redesign as part of pathways of care', and argues for a 'focus on designing and implementing new 'ways of working' and the culture change that accompanies it', without which initiatives often fail. ${ }^{41}$ Within Scotland, legislation to integrate health and social care (Public Bodies (Joint Working) (Scotland) Act 2014) was introduced and as part of this integration agenda there has been increased recognition of the need to include people in improving services through coproduction and cocreation. ${ }^{42-44}$

However, there is little consistency in the language used to encompass public and patient involvement (words include cocreation, codesign, coproduction and others) nor in how it is defined, should be conducted practically and evaluated. ${ }^{45}$ There is no doubt that it can be difficult to know how best to approach patient involvement and much of the research literature is equivocal, not least because of a lack of robust reporting and evaluation of approaches used. ${ }^{46}$ However, there is evidence that both patients and practitioners value being involved, if it is not tokenistic, and that high-level engagement can improve service provision. ${ }^{46} 47$
The literature on how to achieve successful systemwide implementations in practice is currently sparse. This paper helps fill that gap by reporting on the practical application of testing and implementing video consultations for OPA using quality improvement and codesign principles.

\section{MEASUREMENT}

System mapping was used to disaggregate the challenges associated with developing and implementing the new service. A fishbone diagram ${ }^{48}$ was created by the project lead following extensive discussions with stakeholders and this served to highlight the people, processes and root causes of potential variations in the service being developed.

Extensive field notes were taken during stakeholder engagement events and contacts to capture the range of opinion and issues surrounding the introduction of the Near Me intervention. These notes were collated and tabulated.

Details of the area, issue and test cycles using Plan, Do, Study, Act (PDSA) were captured and all feedback was responded to immediately by making changes to the service and tested and captured iteratively in the PDSA test cycles.

Real-time testing took place from January to June 2018. Feedback on the service, including patient experience, was captured through discussions with clinical teams and changes to the Near Me service were made continually in response to this feedback. A formal feedback survey was conducted in June 2018 with both staff and patients and public members (copies of the forms used are included as online supplemental files 1 and 2). Data were entered, collated and analysed using a spreadsheet package. Responses were tabulated to describe participants and their responses to the form questions. All qualitative comments made on the forms were captured verbatim.

\section{DESIGN}

The Near Me intervention was based on four key design components. First, reliable and easily accessible technology. The video consulting service is powered by Attend Anywhere technology, providing outpatient consultations for NHS Highland patients either at home or at a NHS clinic local to the patient, that is, a remote clinic. In some remote clinics there may be healthcare support workers to assist patients with the call. The call can take place using Google Chrome or Safari browsers and is compatible with both Android and Apple devices.

Second, expert quality improvement facilitation. The project was designed and led by a project lead with significant experience in implementing change using improvement methodology; gained through the Scottish Quality and Safety Fellowship Programme, Intermountain Advanced Training Programme in healthcare improvement and Lean Leader training. 
Third, a comprehensive understanding of the system. System mapping ${ }^{49}$ was undertaken to clarify and link factors affecting the creation of the Near Me outpatient service. This served to highlight causes of potential variations in the development and implementation of the service and to identify and begin engagement with key people who would be involved in video consultation.

Fourth, codesign across the system. The overall development of Near Me, within NHS Highland, was founded on a rigorous and ongoing approach of codesign involving and engaging patients and staff. The codesign elements were in two phases, first, design of the service via discussions and demonstrations, and second, real-time testing. Both phases used PDSA cycles to test and learn.

\section{STRATEGY}

The strategy for improvement was based on adopting a whole-system codesign approach involving patients and staff from across NHS Highland in the development and testing of the Near Me service for OPAs, either in patients own homes or at Near Me clinics (ie, local NHS facilities).

Stakeholder engagement was extensive both before and after the service was started. Collaboration was immediate and involved stakeholders from across the community. For example, discussions took place with local politicians to identify any strategic issues and gain their support. Public meetings and other opportunities to present and discuss the idea of video consulting for OPA were sought. Additional public representative input came via NHS Highland communications department and included local politicians as well as local action group members. Initial discussions took place with three clinicians, identified by the project lead as innovators or early adopters. ${ }^{50}$ Multiple meetings were held with staff who played a part in delivering the outpatient process from the patient booking service, clinic builders, appointment coding, medical records, letter writing group, clinic receptionists, medical secretaries, administration managers, clinical service managers, eHealth networks, estates, outpatient staff (at two sites-the main outpatient clinic where the clinicians would be and the remote hospital where many patients would now attend by video), management, planning and performance as well as with external organisations (Attend Anywhere and the Scottish Government's Technology Enabled Care programme). Involvement of clinicians, non-clinical staff and patients was an iterative and ongoing process.

The codesign element of this project was in two phases: first design of the service, and second, real-time testing. Within both phases, there were testing and improvement cycles:

- Phase 1 (before service launch): discussions and testing via demonstrations with public groups which fed into improvement cycles.

- Phase 2 (real-time testing): testing within real appointments, with the feedback from patients/clinicians/ non-clinical staff feeding into improvement cycles.
Testing and improvement cycles were started once the idea of the video consulting appointment had gained initial stakeholder support. PDSA cycles provided a framework to conduct small-scale testing of stakeholder generated ideas for improvement and facilitated the capture of learning to influence next steps. Acting on the PDSA findings proved to staff and patients that their opinions mattered and were essential to the successful implementation of video-consulting technology. Many participants identified that it was only by having something tangible to test that they felt able to contribute ideas and suggestions for change. Clinicians identified suitable patients to test the use of video consulting OPA. Continual testing and learning continued to shape the approach and system of video consulting OPAs. The codesign process led to continual cycles of change, as every element was tested. Each part of each process was tested and refined multiple times before a standard process was agreed. This process was captured by the project lead on an ongoing basis.

Real-time testing started once a standard process had been agreed by the stakeholders and was used to assess the feasibility and acceptability of using video consultations and to determine key enablers to embedding the intervention into routine practice. Three groups were critical in the testing process: clinicians, patients/public and non-clinical staff.

Clinicians willing to test the system were supported individually by the project lead. For example, the project lead individually trained the clinicians in the use of the Near Me new video consulting platform, explanations were given on the process of appointment booking and clinicians were supported during their first use of the video consulting OPA. The project lead gathered feedback from the clinician either in real time or via email.

The project lead captured feedback from public and patients on their experiences of using video consulting, which resulted in continual changes to the service. Patients and clinicians were involved in PDSA cycles, to test and refine aspects of the process. This user involvement included attending virtual appointments, reviewing written materials and deciding on the service nameNear Me. Extensive opinion gathering, was a key part of the codesign approach. This was a reiterative process, as changes were made, feedback was captured to identify further changes to improve and refine the process.

Administrative and managerial staff were engaged in discussions around every element of the service before processes were agreed, tested and refined. Regular governance group meetings were held to track progress and to verify every part of the process against wider knowledge of NHS services.

\section{RESULTS}

Systems mapping involved identifying the people, resource, systems, equipment, processes and environment factors which could have impacted on the successful delivery of the Near Me service. The overall development 
approach of the Near Me service and the fishbone diagram are provided as supplementary files (online supplemental files 3 and 4). These initial steps formed the basis for understanding the context within which the Near Me intervention would be developed and tested, including the potential enablers and barriers to codesign and successful implementation.

Stakeholder engagement and feedback were initiated prior to the Near Me service starting in order to create a video consulting service suitable for testing; over 30 meetings were held with the public, local politicians and councillors, patient groups and NHS staff groups. This engagement continued once the system had gone live to test and continually improve the service so that a service model could be finalised for scale up. Further details of the engagement approaches and who was involved are provided in online supplemental file 5 . The codesign approach helped identify changes needed and barriers to implementation from both a patient/public and staff perspective. This improved relationships and built trust and enabled strategies to be developed to address challenges and to and support the implementation of the new intervention within the existing system.

Table 1 illustrates some of the key testing and improvement cycles in the development of the service (both before service launch and during real-time testing). It is not a comprehensive list of every test cycle undertaken and, in many cases, the item listed below represents five or six individual tests, however the table does demonstrate the breadth of testing work undertaken.

Real-time testing took place from January to June 2018. Eleven clinicians from 10 clinical services were identified to test the service, with patients in real time: cardiology, endocrinology, diabetes (separate to endocrinology), general medical, obstetrics and gynaecology, orthopaedics, psychiatry, respiratory, rheumatology, and stroke and rehabilitation. There were 26 Near Me Clinics during this time and 112 patients were seen.

Clinician survey feedback was received from all 11 clinicians ( $100 \%$ response rate). Few challenges with the quality of the video call were reported, only one of the respondents struggled to hear the patient clearly, and this was resolved during the call, and none struggled to see the patient clearly. However, six reported a problem with the connection.

When asked about the benefits and disadvantages of NHS Near Me, more benefits than disadvantages were reported (see figure 1). Savings in travel time and transportation were particularly noted, as was the saving in clinical time despite the occasional need for additional staff resource to support the patient using the system and, in some cases, appointments taking longer.

All patients, $\mathrm{N}=112$, who had a Near Me consultation during the test phase were given a survey to complete, 34 were returned (response rate $30 \%$ ).

In response to questions about their general experiences of using NHS Near Me, all survey respondents said they found the system easy to use, would use Near Me again and would recommend it to others. Qualitative comments included:

In all cases today, the full consultation was completed satisfactorily by video and patients were thankful for the appointments to have been possible: I was impressed with what we could achieve by Near Me and plan to use the system again.

I have been doing video consultations for four years. The Near Me technology is a huge improvement. Still some patients prefer face-to-face consultations, but the vast majority love its ease and accessibility. It cannot be rolled out fast enough for me.

Examination needs to be done and the Near Me health care support worker was able to do this excellently - though this is additional staffing, it is the key reason why Near Me is better than VC.

The survey also monitored the quality of the video consultation and the responses did identify some technical issues with the system, four patients reported a problem with the connection and/or with hearing the clinician, however, there were no reported issues in seeing the clinician clearly.

Figure 2 shows patient responses to questions about the benefits and disadvantages to them of the Near Me system. Consistent with clinician's responses, savings related to travel was seen by most as a benefit. One patient would have preferred a face-to-face consultation regardless of the need to travel, and two patients needed to see the consultant in person following the video consultation.

Patients reported positive experiences of using NHS Near Me. Although four had reported that they had not found the system easy to use, all patients reported that they would be happy to use Near Me again. Many of the qualitative comments related to the reduced travel time and the benefits to patients who felt unwell, and to their families in terms of time together. The comments included:

Very thankful not to have to travel to Inverness for a 10-minute consultation

It's a first class idea, very well organised

Very definitely use again

It was fine as nurse in room to help

I wish this service had been in place when my husband was alive. We spent the last year of his life driving up and down to Raigmore for hospital appointments. Avoiding this would have given us much more quality time together before he died.

Being able to attend my appointment locally was much easier. I was impressed with the quality of the video call: the picture and sound were really clear; it was like being in the same room as the consultant.

When my Mum was diagnosed with cancer, she had to travel back here on her own which was distressing. If she had been given an appointment by NHS Near 
Table 1 Quality improvement test cycles in the development of the Near Me video consultation service for outpatients

\begin{tabular}{|c|c|c|}
\hline Area & Issue & Test cycles \\
\hline Patient access & $\begin{array}{l}\text { Patients confused by different URLs } \\
\text { for different clinical services, and data } \\
\text { protection issues with emailing patients } \\
\text { Poor internet connectivity at patients' } \\
\text { home (see also Pharmacy Anywhere } \\
\text { section below) } \\
\text { Confusion over patient appointment } \\
\text { letters }\end{array}$ & $\begin{array}{l}\text { Created single website entry point, tested design and } \\
\text { content } \\
\text { Introduced Near Me clinics in NHS premises (phase 1) } \\
\text { Multiple letters tested to try to reach clarity on location } \\
\text { of clinic and information about Near Me service, within } \\
\text { constraints of TrakCare electronic medical record } \\
\text { system options }\end{array}$ \\
\hline Virtual receptionist & $\begin{array}{l}\text { Who should undertake the virtual } \\
\text { receptionist role } \\
\text { Patient transferred to incorrect waiting } \\
\text { area } \\
\text { - Unscheduled calls }\end{array}$ & $\begin{array}{l}\text { Tested role in patient booking service then outpatient } \\
\text { reception team } \\
\text { Introduced patient identification via TrakCare } \\
\text { System for unscheduled calls introduced }\end{array}$ \\
\hline $\begin{array}{l}\text { Clinic room } \\
\text { Booking and } \\
\text { scheduling }\end{array}$ & $\begin{array}{l}\text { Need for single system for anyone to } \\
\text { book rooms } \\
\text { Need for multiple clinical services to } \\
\text { run Near Me clinics at remote sites at }\end{array}$ & $\begin{array}{l}\text { Tested system in Computer Aided Booking System } \\
\text { Multiple versions of schedule produced. Most complex } \\
\text { part of system }\end{array}$ \\
\hline
\end{tabular}
any one time

$\begin{array}{ll}\text { Clinic rooms for } & \text { Need for rooms to be appropriately } \\ \text { consultants } & \text { equipped } \\ & \text { Image clarity was poorer with tablets } \\ & \text { than with computers } \\ & \text { Device settings kept being changed } \\ \text { Clinic rooms at remote } & \text { Need to create Near Me clinic rooms } \\ \text { site } & \text { from disused office space } \\ & \text { Screen size, webcam selection, angling } \\ & \text { of cameras, speakers etc identified } \\ & \text { issues } \\ & \text { Identification of correct clinical } \\ & \text { equipment }\end{array}$

Clinical support
Clinical services identified need for
appropriate clinical support in calls
Defining role, creation of job description
Training of healthcare support worker
Systems needed to enable remote
authorisation by clinicians

Standard service manual
- Need to create a single service manual for NHS Near Me to deliver consistent service and reduce variation

- Need to make manual widely available
Tested various types of equipment

- Use computer and webcam instead of tablet in clinic rooms

- Introduced system for checking settings before clinics

- Tested single room before defining estates specification. This included testing different lighting, flooring, sound reduction, paint colours.

- Tested various types of equipment-larger screens installed, tested various webcams, tested clip tripod and various speakers

- Ran multiple clinics with multiple services to identify all clinical equipment needed, trolley with list defined, plus large equipment (examination couch, bins, privacy screen, etc)

- Role developed over multiple clinics, as full extent of role became clear (different for each service)

- Role and job description drafted and refined with each clinical service. Role linked into existing outpatient department

- Core training defined with further training on a service by service basis

- Testing systems for remote requesting of blood tests and images

- Single process manual created involving 21 key contributors and many more other contributors. Went through multiple tests of change, from 6-page starting point in Jan 2018 to final 39-page document in May 2018.

- Intranet site for manual tested and simplified following feedback 
Table 1 Continued

\begin{tabular}{lll}
\hline Area & Issue & Test cycles \\
\hline Resources & $\begin{array}{l}\text { Need for guides for patients, } \\
\text { clinicians, virtual receptionists plus }\end{array}$ & Guides created and tested, refined and then added to \\
troubleshooting guide & intranet site \\
& Need for public relations & Presentation given at 20+ events, refined each time. \\
& & Film created and then shorter version created on \\
& feedback. \\
& Twitter account created
\end{tabular}

NHS, National Health Service.

Me, she would have got home much more quickly, and we could have been at the appointment with her.

Another output of the codesign process, was the development of a single standard process manual, encompassing the many component parts of the Near Me service, the production of which was overseen by a Near Me governance group, including senior level NHS Board operational directors, e-health and technology leads and heads of service. The codevelopment of a standard process supported Near Me adoption and spread across clinical services within the hospital system. A standardised approach, made the running of outpatient clinics easier for staff (eg, appointment booking staff, reception staff, clinical records) and for it to be embedded within the existing patient management system (in NHS Highland this is TrakCare). Near Me codes, within the system, enabled Near Me appointments to be treated in the same manner as all OPAs and ensured that any additional documentation was automatically generated. By automating the process through this coding approach, the amount of work required by administrative and clinic staff to organise clinics was reduced, compared with a traditional remote clinic.

\section{LESSONS AND LIMITATIONS}

This paper describes the development and implementation of video consultations to facilitate remote OPA using a quality improvement approach that put the users at the centre of the design and optimisation process. It highlights how codesign and QI approaches can be used to navigate the complex social systems in which healthcare operates. Moreover, it bridges a gap in the existing QI literature, which tends to focus solely on reporting the outcomes of improvement interventions, by providing details of the approach to how this intervention was designed and implemented successfully.

Key to the success of Near Me was the whole-system codesign approach adopted. Robert and MacDonald capture the essence of this codesign space as necessary for 'collective, open discourse where prevailing hierarchies and predominant modes of thinking can be challenged

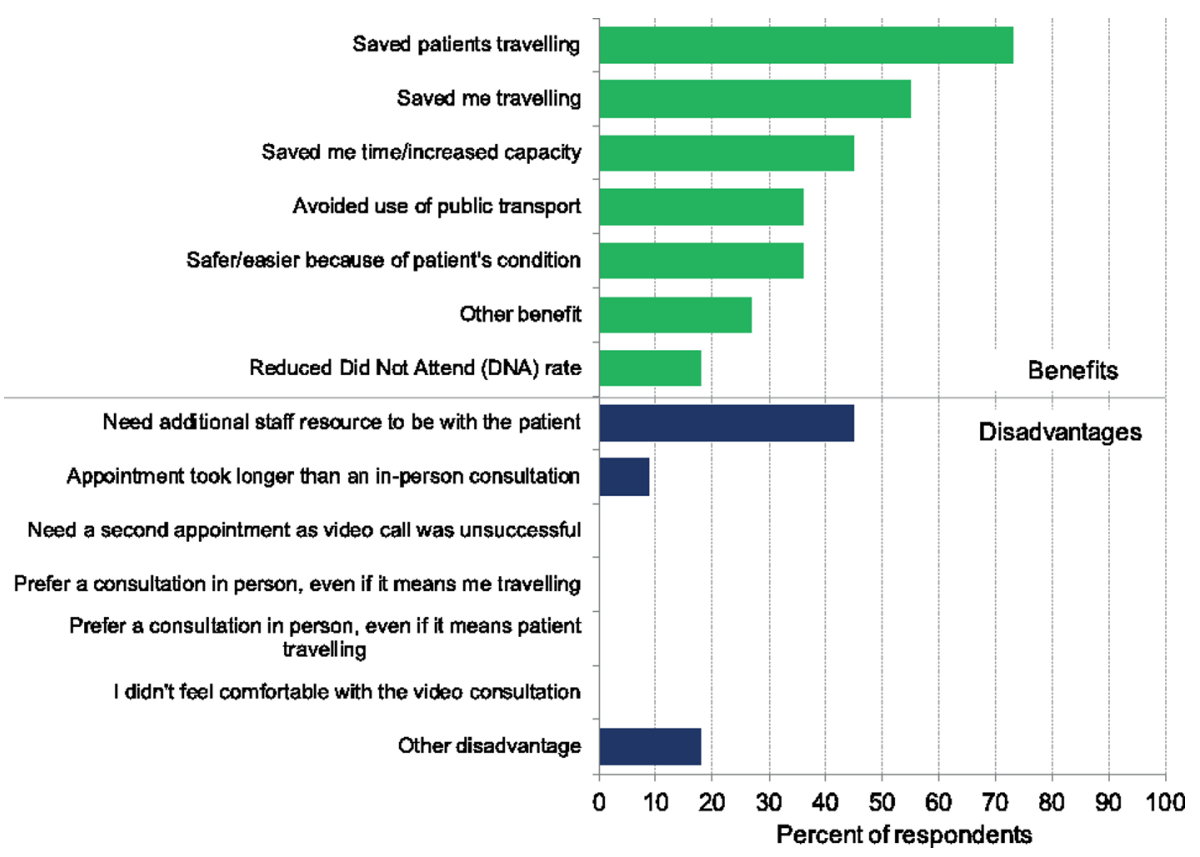

Figure 1 Clinician reported benefits and disadvantages of using the NHS Near Me system for outpatient appointments. NHS, National Health Service. 


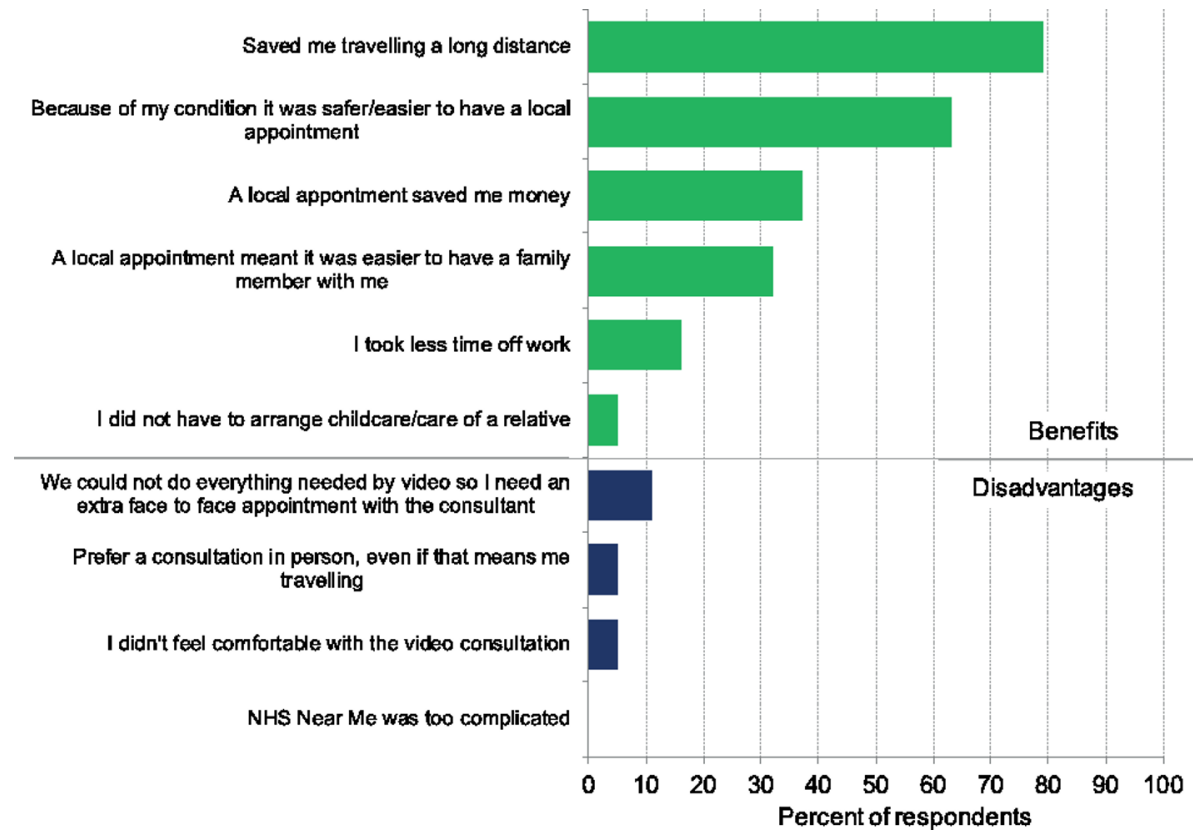

Figure 2 Patient reported benefits and disadvantages of using the NHS Near Me system for outpatient appointments. NHS, National Health Service.

and suspended' and 'where differing views of 'evidence' and 'knowledge' are not mutually exclusive. ${ }^{51}$

Genuine collaboration, where everyone's views were equally valid and acted on was the keystone of this project. Working with clinicians, non-clinical staff and patients as partners; they were not 'told' how to use the system, rather the project lead created a collaborative space to work with, learn from and adapt the use of Near Me with the people who would ultimately use it. The standard process for Near Me works because it was designed by patients, front-line and administrative staff, with management involvement and support, and therefore has buy-in from across the system. The involvement of stakeholders in the design and testing of processes and technology on a repeated basis maximised the likelihood of the new service model being acceptable, appropriate and feasible and made the task of embedding the technology as a new routine way of working easier.

Widescale, comprehensive and systematic stakeholder engagement facilitated 'buy-in' to the concept of remote consultations and the use of technology to enable these. Importantly, concerns were not dismissed, rather they were used to 'test' out the theory on which the issue was raised. For example, where clinicians were concerned that the use of Near Me may not be suitable for all OPA, a step was added into the Near Me system where the clinician determined the suitability of a video consultation prior to booking. Notably, all respondents, both patients and clinicians, who tested the technology and gave feedback reported that they would be happy to use the system again. The collaborative approach adopted in this project is consistent with current theories of how largescale, change can be achieved and with how ensuring and demonstrating harmony between intrinsic and external motivators for change, successful change can be sustained. ${ }^{52}$

There were some limitations, particularly in relation to capturing the rationale for some of the decisions made. In addition, informal verbal feedback from participants was obtained in calls and, although a written survey was offered to each patient, not all returned them, so it is difficult to gauge the extent to which the Near Me intervention was or would be universally accepted. It may be that those who participated in patient group, council and public meetings and those who completed the questionnaires differed from those who did not. Much of the early work involved the capturing of opinion on the process developed to date, and what changes were needed to improve it. As changes were made, further conversations and testing took place, however why some of these decisions were made has not been documented. Notwithstanding these limitations, the way in which these approaches were implemented is replicable and this report provides a template for others to use, adapt and learn from.

A final weakness is that demographic groups were not specifically studied. During the initial coproduction phase before the service went live, there was an open public invitation for anyone to participate. Local councillors were approached in an attempt to capture a population-wide view. In the second phase of live testing, appointments were offered to anyone who had an OPA that was clinically appropriate for video consultation. Appointments were not selected for any demographic group and demographics were not recorded. Despite this weakness, useful work has been done since by the Scottish government on a national public engagement exercise ${ }^{53}$ and equality impact assessment ${ }^{54}$ on video consulting (with 
the involvement of one of this paper's authors). These reports demonstrate that there is no demographic group that video consultations specifically disadvantage: for every group, there are some individuals for whom it is an advantage and others for whom it is not. This challenges many of the assumptions made about video consulting, and supports the approach taken by this study of offering an appointment to every patient for whom it was clinically appropriate.

\section{CONCLUSION}

This paper reports on a system-wide quality improvement project drawing on the principles and methods of codesign for the local embedding and use of a video technology platform for remote consulting, at scale across a large health board. Drawing on this study, we provide transferable lessons to help support the local development of similar services and a more generalisable approach to service (re)development through QI and codesign. The process of introducing the initiative and the extensive involvement of all stakeholders in the meaningful codesign of the new service is provided in detail. The COVID-19 pandemic has brought into sharp focus the need to innovate the ways in which health services can safely and effectively be provided and the use of video consultation has grown, and will continue to grow, for clinically appropriate conditions. Across Scotland, use of video consultations has expanded from around $300 \mathrm{a}$ week in February 2020 to 16000 a week in June 2020. ${ }^{55}$ The insights and lessons learnt within this QI project have informed the approach taken to the national scale up of video consulting in Scotland in response to COVID-19, and will continue to be useful to those attempting to instigate, scale and sustain video consultations now and in the future.

\section{Author affiliations}

${ }^{1}$ Royal Pharmaceutical Society Scotland, Edinburgh, UK

${ }^{2}$ Department of Nursing, University of the Highlands and Islands, Inverness, UK

${ }^{3}$ Nuffield Department of Primary Care Heal, University of Oxford, Oxford, UK

${ }^{4}$ Consultant in Public Health Medicine, Department of Public Health, NHS Highland, Inverness, Scotland

${ }^{5}$ Honorary Reader \& Lecturer Pg Cert Healthcare Quality Improvement, Lews Castle College, University of the Highlands and Islands, Stornoway, Scotland

${ }^{6} \mathrm{NHS}$ National Services Scotland, Edinburgh, UK

${ }^{7}$ Highland Alcohol and Drugs Partnership, NHS Highland, Inverness, UK

${ }^{8}$ Scottish Improvement Science Collaborating Centre (SISCC), School of Health

Sciences, University of Dundee, Dundee, UK

Twitter Michelle Beattie @BeattieQi

Contributors $\mathrm{CM}$ designed the project and was responsible for the collection of data. CM, MB, JW, CS, JA, CH-R and NMG contributed to the interpretation of data. NMG led the drafting of the paper. CM, MB, JW, CS, JA, CH-R and NMG reviewed and contributed to numerous drafts and all provided final approval of the submitted article.

Funding The development of Near Me described within this paper including staff and equipment was part-funded by NHS Highland and part-funded by the Scottish Government's Technology Enabled Care programme.

Competing interests None declared.

Patient consent for publication Not required.
Provenance and peer review Not commissioned; externally peer reviewed.

Data availability statement All data relevant to the study are included in the article or uploaded as supplementary information.

Supplemental material This content has been supplied by the author(s). It has not been vetted by BMJ Publishing Group Limited (BMJ) and may not have been peer-reviewed. Any opinions or recommendations discussed are solely those of the author(s) and are not endorsed by BMJ. BMJ disclaims all liability and responsibility arising from any reliance placed on the content. Where the content includes any translated material, BMJ does not warrant the accuracy and reliability of the translations (including but not limited to local regulations, clinical guidelines, terminology, drug names and drug dosages), and is not responsible for any error and/or omissions arising from translation and adaptation or otherwise.

Open access This is an open access article distributed in accordance with the Creative Commons Attribution Non Commercial (CC BY-NC 4.0) license, which permits others to distribute, remix, adapt, build upon this work non-commercially, and license their derivative works on different terms, provided the original work is properly cited, appropriate credit is given, any changes made indicated, and the use is non-commercial. See: http://creativecommons.org/licenses/by-nc/4.0/.

\section{ORCID iD}

Nicola M Gray http://orcid.org/0000-0001-8497-394X

\section{REFERENCES}

1 Scotland NRo. Mid-year population estimates, Scotland 2019

2 Increasing the use of telehealth for outpatient appointments, 2017

3 Health_Foundation. Pharmacy anywhere. Available: https://www. health.org.uk/improvement-projects/pharmacy-anywhere

4 Naiker U, FitzGerald G, Dulhunty JM, et al. Time to wait: a systematic review of strategies that affect out-patient waiting times. Aust Health Rev 2018;42:286-93.

5 Deloitte Touche Tohmatsu Limited. 2019 global health care outlook shaping the future. Available: https://www2.deloitte.com/content/ dam/Deloitte/global/Documents/Life-Sciences-Health-Care/gx-Ishchc-outlook-2019.pdf

6 NHS Digital. Hospital outpatient activity 2018-19, 2019.

7 Public Health Scotland. Outpatient activity. Available: https://www. isdscotland.org/Health-Topics/Hospital-Care/Outpatient-Activity/

8 Scottish Government. The modern outpatient: a collaborative approach 2017-2020. 2016. Edinburgh, 2016.

9 Campbell KMA, McCartney G, McCullough S. Who is least likely to attend? An analysis of outpatient appointment 'Did Not Attend' (DNA) data in Scotland. 2015. Edinburgh: NHS Health Scotland, 2015.

10 NHS England. NHS long term plan, 2019.

11 Scottish Government. Protecting Scotland's Future: the Government's Programme for Scotland 2019-2020, 2019.

12 Scottish Government. Health and social care delivery plan. Edinburgh: Scottish Government, 2016.

13 Armfield NR, Bradford M, Bradford NK. The clinical use of Skype-For which patients, with which problems and in which settings? A snapshot review of the literature. Int J Med Inform 2015;84:737-42.

14 Gentles SJ, Lokker C, McKibbon KA. Health information technology to facilitate communication involving health care providers, caregivers, and pediatric patients: a scoping review. J Med Internet Res 2010;12:e22.

15 Greenhalgh T, Vijayaraghavan S, Wherton J, et al. Virtual online consultations: advantages and limitations (vocal) study. BMJ Open 2016;6:e009388.

16 Freeman KA, Duke DC, Harris MA. Behavioral health care for adolescents with poorly controlled diabetes via Skype: does working alliance remain intact? J Diabetes Sci Technol 2013;7:727-35.

17 Harris MA, Freeman KA, Duke DC. Seeing is believing: using Skype to improve diabetes outcomes in youth. Diabetes Care 2015;38:1427-34.

18 Somers TJ, Kelleher SA, Westbrook KW, et al. A small randomized controlled pilot trial comparing mobile and traditional pain coping skills training protocols for cancer patients with pain. Pain Res Treat 2016;2016:2473629.

19 Katz IJ, Pirabhahar S, Williamson P, et al. iConnect CKD - virtual medical consulting: A web-based chronic kidney disease, hypertension and diabetes integrated care program. Nephrology 2018;23:646-52.

20 Newman SD, Toatley SL, Rodgers MD. Translating a spinal cord injury self-management intervention for online and telehealth delivery: a community-engaged research approach. J Spinal Cord Med 2019;42:595-605. 
21 Shem K, Sechrist SJ, Loomis E, et al. SCiPad: effective implementation of telemedicine using iPads with individuals with spinal cord injuries, a case series. Front Med 2017;4:58.

22 Nield M, Hoo GWS. Real-time telehealth for COPD self-management using Skype ${ }^{\mathrm{TM}}$. COPD 2012;9:611-9.

23 Mark DD, Ikehara C, Matsuura C, et al. Validating the impact of teaching Pursed-Lips breathing with Skype. J Hospice Palliat Nurs 2013;15:424-32

24 Choi NG, Hegel MT, Marti N, et al. Telehealth problem-solving therapy for depressed low-income homebound older adults. Am J Geriatr Psychiatry 2014;22:263-71.

25 Chavooshi B, Mohammadkhani $\mathrm{P}$, Dolatshahi B. A randomized double-blind controlled trial comparing Davanloo intensive shortterm dynamic psychotherapy as internet-delivered vs treatment as usual for medically unexplained pain: a 6-month pilot study. Psychosomatics 2016;57:292-300.

26 Pennington L, Stamp E, Smith J, et al. Internet delivery of intensive speech and language therapy for children with cerebral palsy: a pilot randomised controlled trial. BMJ Open 2019;9:e024233.

27 Bennell KL, Nelligan R, Dobson F, et al. Effectiveness of an internetdelivered exercise and Pain-Coping skills training intervention for persons with chronic knee pain: a randomized trial. Ann Intern Med 2017; 166:453-62.

28 Müller KI, Alstadhaug KB, Bekkelund SI. Acceptability, feasibility, and cost of telemedicine for nonacute headaches: a randomized study comparing video and traditional consultations. J Med Internet Res 2016;18:e140.

29 Ekberg S, Danby S, Theobald M, et al. Using physical objects with young children in 'face-to-face' and telehealth speech and language therapy. Disabil Rehabil 2019;41:1664-75.

30 Krout RE, Baker FA, Muhlberger R. Designing, Piloting, and evaluating an on-line collaborative Songwriting environment and protocol using Skype Telecommunication technology: perceptions of music therapy student participants. Music Therapy Perspectives 2010;28:79-85.

31 Fairweather GC, Lincoln MA, Ramsden R. Speech-language pathology teletherapy in rural and remote educational settings: decreasing service inequities. Int J Speech Lang Pathol 2016;18:592-602.

32 Westra I, Niessen FB. Implementing real-time video consultation in plastic surgery. Aesthetic Plast Surg 2015;39:783-90.

33 Shaw S, Wherton J, Vijayaraghavan S. Health services and delivery research. Advantages and limitations of virtual online consultations in a NHS acute trust: the vocal mixed-methods study. Southampton, UK: NIHR Journals Library, 2018.

34 Greenhalgh T, Shaw S, Wherton J, et al. Real-World implementation of video outpatient consultations at macro, meso, and micro levels: Mixed-Method study. J Med Internet Res 2018;20:e150.

35 Greenhalgh T, Wherton J, Shaw S, et al. Infrastructure revisited: an ethnographic case study of how health information infrastructure shapes and constrains technological innovation. J Med Internet Res 2019;21:e16093.

36 Donaghy E, Atherton H, Hammersley V, et al. Acceptability, benefits, and challenges of video consulting: a qualitative study in primary care. Br J Gen Pract 2019;69:e586-94.

37 Shaw SE, Seuren LM, Wherton J, et al. Video consultations between patients and clinicians in diabetes, cancer, and heart failure services: linguistic ethnographic study of Video-Mediated interaction. J Med Internet Res 2020;22:e18378.

38 Seuren LM, Wherton J, Greenhalgh T, et al. Physical examinations via video for patients with heart failure: qualitative study using conversation analysis. J Med Internet Res 2020;22:e16694.

39 Arminen I, Licoppe C, Spagnolli A. Respecifying mediated interaction. Res Lang Soc Interact 2016;49:290-309.

40 Scottish Government. Scotland's Digital Health \& Care Strategy. Enabling, Protecting \& Empowering. Scottish Government, 2018.

41 Scottish Government. The modern outpatient: a collaborative approach 2017-2020. Edinburgh, 2017.

42 Evaluation Support Scotland. Evidencing genuine co-production in the third sector. Edinburgh, 2017.

43 Health and Social Care Alliance Scotland. Co-production activity review of 2017, 2018.

44 Healthcare Improvement Scotland. iHub who we are, 2020. Available: https://ihub.scot/about-us/who-we-are/

45 John Connolly DSM, Munro DA, Mulherin DT. How co-production and co-creation is understood, implemented and sustained as part of improvement programme delivery within the health and social care context in Scotland. Scottish Improvement Science Collaborating Centre, 2020.

46 Clarke D, Jones F, Harris R, et al. What outcomes are associated with developing and implementing co-produced interventions in acute healthcare settings? A rapid evidence synthesis. BMJ Open 2017;7:e014650.

47 Bombard Y, Baker GR, Orlando E, et al. Engaging patients to improve quality of care: a systematic review. Implement Sci 2018;13:98.

48 Ishikawa K. Guide to quality control. Tokyo: Asian Productivity Organization, 1976.

49 Johnson KE, Kamineni A, Fuller S, et al. How the provenance of electronic health record data matters for research: a case example using system mapping. EGEMS 2014;2:4.

50 Rogers EM. Diffusion of innovations. 5th edn. New York: Free Press, 2003.

51 Robert GB, Macdonald A. Chapter 9. Co-design, organisational creativity and quality improvement in the healthcare sector 'designerly' or 'design-like'? In: Sangiorgi D, Prendiville A, eds. Designing for service key issues and new directions. London: Bloomsbury Academic, 2017.

52 Breckenridge JP, Gray N, Toma M, et al. Motivating Change: a grounded theory of how to achieve large-scale, sustained change, co-created with improvement organisations across the UK. BMJ Open Qual 2019;8:e000553.

53 Scottish Government. Video consultations - public and clinician views: consultation summary. Available: https://www.gov.scot/ publications/public-clinician-views-video-consultation-executivesummary/

54 Scottish Government. Near me video consulting programme: equality impact assessment. Available: https://www.gov.scot/publications/ near-video-consulting-programme-national-equality-impactassessment/

55 Near me: summary of the 12-week scale up for COVID-19, 2020. Available: https://tec.scot/wp-content/uploads/2020/07/Near-Mereview-of-12-week-scale-up.pdf 